\title{
Quality and chemical profiles of virgin olive oils of three European cultivars suitable for super-high-density planting conditions in eastern Morocco
}

Article in Materials today: proceedings · January 2019

DOI: $10.1016 /$ j.matpr.2019.04.065

CITATIONS

0

8 authors, including:

Farid Mansouri

Université Mohammed Premier

42 PUBLICATIONS 52 CITATIONS

$$
\text { SEE PROFILE }
$$

Aazza Smail

Universidade Federal de Lavras (UFLA)

58 PUBLICATIONS 396 CITATIONS

SEE PROFILE
READS

24

Abdessamad BEN Moumen

Université Mohammed Premier

27 PUBLICATIONS 51 CITATIONS

SEE PROFILE

Kamal Belhaj

Université Mohammed Premier

24 PUBLICATIONS 1 CITATION

SEE PROFILE

Some of the authors of this publication are also working on these related projects:

Biochemical characterization of Anisophyllea boehmii kernel oil View project

Maroc/Wallonie Bruxelles Coopération bilatérale : Axe 1 : Projet 6/ Gestion de la qualité des aliments cas de la viande de la race Ovine Bni Guil , labellisée IGP de l'oriental du Maroc View project 


\section{ScienceDirect}

Materials Today: Proceedings 13 (2019) 998-1007 $\underset{\text { MROCEREDINGS }}{\text { materialsa: }}$

www.materialstoday.com/proceedings

ICMES 2018

\title{
Quality and chemical profiles of virgin olive oils of three European cultivars suitable for super-high-density planting conditions in eastern Morocco
}

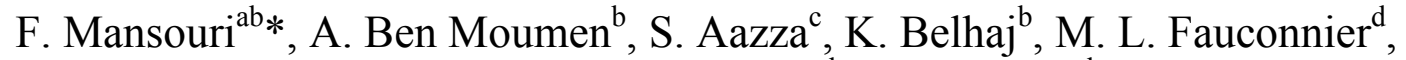 \\ M. Sindic ${ }^{\mathrm{e}}$, H. Serghini Caid ${ }^{\mathrm{b}}$, A. Elamrani ${ }^{\mathrm{b}}$ \\ ${ }^{a}$ Laboratory of Biochemistry, National Agency of Medicinal and Aromatic Plants, BP-159, 34000 Taounate, Morocco. \\ ${ }^{b}$ Laboratory of Plants and Microorganisms Biology, Faculté des Sciences - Université Mohammed Premier, BP-717, 60000 Oujda, Morocco. \\ ${ }^{c}$ Laboratory of Phytochemistry, National Agency of Medicinal and Aromatic Plants, BP-159, 34000 Taounate, Morocco. \\ ${ }^{d}$ General and Organic Chemistry Unit, Gembloux Agro-Bio Tech - Université de Liège, Passage des Déportés 2, 5030 Gembloux, Belgium. \\ ${ }^{c}$ Analysis Quality and Risk Unit, Laboratory of Food Quality and Safety, Gembloux Agro-Bio Tech - Université de Liège, Belgium.
}

\begin{abstract}
This study aims to evaluate the quality and chemical composition of virgin olive oils of Greek (Koroneiki) and Spanish (Arbequina and Arbosana) varieties grown in north-eastern Morocco under irrigated super-high-density planting system, via the study of their minor compounds, fatty acid and triacylglycerol compositions, and oxidative stability. The majority of the evaluated parameters are influenced by varietal and environmental factors. The studied varieties produced good quality oils with a chemical composition that meets the requirements of the International Olive Council. Koroneiki oil has the highest levels of total phenols $\left(530 \mathrm{mg} \mathrm{kg}^{-1}\right)$ and $\mathrm{C} 18: 1(76.70 \%)$ as well as the better stability to oxidation (98.64h). Arbosana oil is distinguished by the abundance of tocopherols $\left(449.27 \mathrm{mg} \mathrm{kg}^{-1}\right)$ and an intermediate oxidative stability $(74.49 \mathrm{~h})$. The highest phytosterol content was recorded in Arbequina oil $\left(1971 \mathrm{mg} \mathrm{kg}^{-1}\right)$. Eleven phenolic compounds were identified and quantified. Decarboxymethylated forms of oleuropein aglycone and ligstroside aglycone were the main components in all the analyzed oils (95-165 mg kg${ }^{-1}$ and $115-181 \mathrm{mg} \mathrm{kg}^{-1}$, respectively).The results of principal component analysis show a clear discrimination between the studied varieties according to antioxidant parameters, triacylglycerol and phytosterol data.
\end{abstract}

(C) 2019 Elsevier Ltd. All rights reserved.

Peer-review under responsibility of the scientific committee of the International Conference on Materials and Environmental Science, ICMES 2018.

Keywords: Fatty acids; Irrigated super-high-density planting; Oxidative stability; Phenolic compounds; Phytosterols; Virgin olive oil.

\footnotetext{
* Corresponding author. Tel: +212 664469 076; Fax: +212 536500603

E-mail address: f.mansouri@ump.ac.ma
} 


\section{Introduction}

Virgin olive oil (VOO) is widely recognized for its virtues and benefits on human health. Its specific fatty acid composition and high content of natural antioxidants are the pillars of its benefits [1]. Phenolic compounds are the main antioxidants of VOO. Secoiridoid derivatives, phenolic acids, phenolic alcohols, lignans and flavonoids are the most important classes of these compounds in VOO [2]. These compounds improve olive oil stability and modulate its flavor $[3,4]$. Tocopherols are also part of the antioxidants found in VOO. They constitute a lipophilic antioxidant group known for its effective inhibition of lipid oxidation. $\alpha$-Tocopherol represents more than $95 \%$ of the total content of tocopherols in VOO [5]. Phytosterols, which are known for their biological effects, such as blood cholesterol control [6], constitute the major portion of the VOO's unsaponifiable matter. Their effects on oil stability are frowned upon, but they act as inhibitors of polymerization reactions [7]. 4-Desmethylsterol is the main group of phytosterols in VOO.

The quantitative and qualitative chemical composition of VOO is affected by many factors such as agronomical and technical factors. They mainly include the genetic factor, pedoclimatic factor related to geographical area, maturation degree, irrigation, crop season and processing methods [8-11].

The olive sector in Morocco plays a very important economic and social role. According to the International Olive Council, Morocco is the world's fourth largest exporter and producer of olive oil after the European Union, Tunisia and Turkey. The Moroccan olive sector finds its future opportunity in increasing global demand for olive oil coupled with Moroccan agricultural policy through green Morocco plan. It plans to extend the area of olive trees from 0.76 to 1.22 million Ha for the period from 2008 to 2020, adopting a high-density planting system. This system allows for intensification of production with planting densities of up to 2500 trees/Ha. This planting system was developed with the aim of ensuring an early entry into production, from the $3^{\text {rd }}$ year of planting, to stabilize the yield from the $5^{\text {th }}$ year of planting ( 8 to 10 tonnes/Ha/year), to mechanize the production and minimize harvesting costs [12]. Among the olive cultivars adapted to intensive cultivation, three have been recently introduced in Morocco; one of Greek origin: Koroneiki and two of Spanish origin: Arbequina and Arbosana.

The new varieties or varieties from other environments must be properly evaluated. Therefore, we have found it interesting to study the quality and composition of olive oils of Greek (Koroneiki) and Spanish (Arbequina and Arbosana) varieties grown under the pedoclimatic conditions of north-eastern Morocco. For this purpose, we evaluate, in this study, the quality and composition of fatty acids, triacylglycerols, phytosterols, tocopherols, phenolic compounds and oxidative stability of virgin olive oils of these three varieties in order to acquire a knowledge of the quantitative and qualitative profiles of these compounds in samples obtained from two successive crop seasons (2012/2013 and 2013/2014).

\section{Materials and methods}

\subsection{Olive oil samples}

Samples of olive oils are taken from three cultivars grown in north-eastern Morocco in two successive crop seasons (2012/2013 and 2013/2014): Koroneiki as a Greek variety; Arbosana and Arbequina as Spanish varieties. These three cultivars have been grown since 2007 (total olive growing area: $60 \mathrm{Ha}$ ) in a private area (Société Huiles d'Olive de la Méditerranée-Oujda) located in north-eastern Morocco (Longitude: $001^{\circ} 57^{\prime} \mathrm{W}$, latitude: $34^{\circ} 47^{\prime} \mathrm{N}$ and altitude: $458 \mathrm{~m}$ ). The climatic data summarized in Figure 1 (accumulated rainfall and min and max temperatures) of the Angad plain were measured daily for two years (2012 and 2013). These data were obtained by la Direction Régionale de la Météorologie Région Nord-Est at Oujda-Angad Airport (Longitude: $001^{\circ} 56^{\prime} \mathrm{W}$, Latitude: $34^{\circ} 47^{\prime} \mathrm{N}$ and Altitude: $463 \mathrm{~m}$ ). The plantations of these varieties (99960 plants) are conducted under irrigated super-highdensity planting system with a density of 1666 trees/Ha and the distances between trees are $1.5 \mathrm{~m} / 4 \mathrm{~m}$. The period of irrigation was the same for all three cultivars, from January to September with a daily flow of $1.2 \mathrm{~L} \mathrm{~h}^{-1}$.

For each season, three samples were taken from each variety, each covering ten trees (approximately one sample is comprised $350 \mathrm{~kg}$ of olives). The olives were harvested at the end of November with a maturity index of 3.8-4.0. The mechanically harvested olives by a straddle are immediately milled by a Pieralisi industrial system (Pieralisi Maip SPA, Jesi (Ancona) Italy) in the Huiles d'Olive de la Méditerranée company. The olive oil samples were then stored in dark glass bottles without headspace in the dark at $4{ }^{\circ} \mathrm{C}$ prior to analysis. 


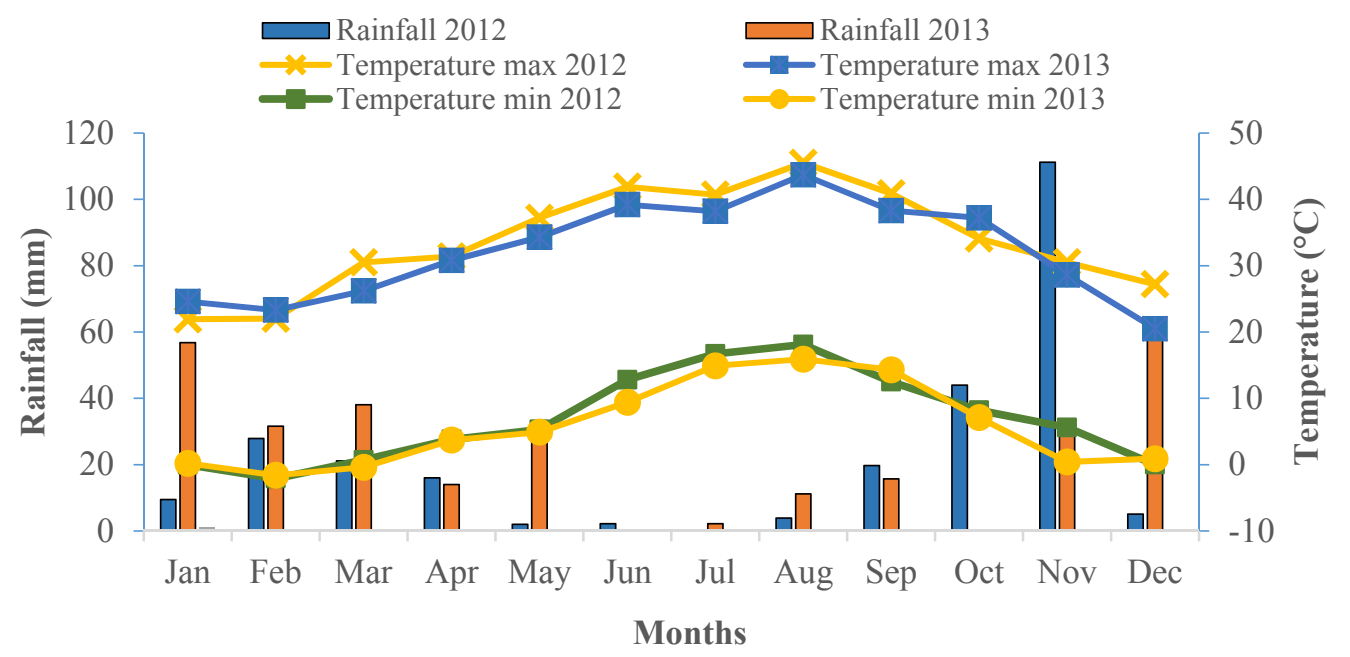

Fig. 1 Monthly rainfall and air temperature during 2012 and 2013 in north-eastern Morocco.

\subsection{Acidity, peroxide value, UV indices and oxidative stability determinations}

Acidity, peroxide value and ultraviolet indices of the oil samples were determined according to the analytical methods (EEC/2568/91) described in the European Commission regulations [13].

The oxidative stability of olive oil was evaluated by the Rancimat test using Metrohm Rancimat 743 (Metrohm Co., Basel, Switzerland) and expressed in induction time (hours). The operating conditions are as follows: $3 \pm 0.01 \mathrm{~g}$ of olive oil sample were subjected to thermal degradation at $100 \pm 1.6^{\circ} \mathrm{C}$ by bubbling a stream of air $\left(15 \mathrm{~L} \mathrm{~h}^{-1}\right)$.

\subsection{Fatty acid analysis}

The fatty acids were analyzed after conversion into methyl esters obtained by transesterification of triacylglycerols according to the method described by Ben Moumen et al. [14]. Fatty acid methyl esters are separated, identified and quantified by gas chromatography (HP 6890 series GC system) equipped with a capillary column (Supelco, Bellefonte, PA, USA) Omega wax $(30 \mathrm{~m} \times 0.25 \mathrm{~mm}, 0.25 \mu \mathrm{m}$ film thickness) and coupled to a

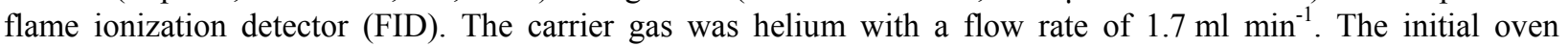
temperature was $50{ }^{\circ} \mathrm{C}$ and it was then increased at a rate of $30{ }^{\circ} \mathrm{C} \mathrm{min}^{-1}$ to $150{ }^{\circ} \mathrm{C}$ followed by an increase of $4{ }^{\circ} \mathrm{C}$ $\min ^{-1}$ to $240{ }^{\circ} \mathrm{C}$.

\subsection{Triacylglycerol analysis}

The determination of triacylglycerol composition was carried out according to the method of Ben Moumen et al. [14].Olive oil solution in acetone were fractionated by a Shimadzu LC-6AD HPLC system (Nakagyo-Ku, Koyoto, Japan) connected to two LC-10AD Shimadzu liquid chromatography pumps and a refractive index detector 10A. The isocratic separation was carried out using an ODS-C18 reverse phase column $(250 \times 4.6 \mathrm{~mm}, 5 \mu \mathrm{m}$ particle size; Thermo Scientific, Waltham, MA, USA). The mobile phase was composed of acetone and acetonitrile $(63.6 / 36.4 ; \mathrm{v} / \mathrm{v})$ at a flow rate of $1 \mathrm{ml} \mathrm{min}^{-1}$.

\subsection{Phytosterol analysis}

The qualitative and quantitative phytosterol contents were determined according to the method described by Ben Moumen et al. [15] in the presence of butilin (Sigma-Aldrich, St. Louis, MO, USA), as an internal standard, at a concentration of $1 \mathrm{mg} \mathrm{ml}^{-1}$. Phytosterols were analyzed by GC-FID (HP 6890 series GC system) equipped with a capillary column HP $5 \mathrm{~ms}(30 \mathrm{~m} \times 0.25 \mathrm{~mm}, 0.25 \mu \mathrm{m}$; Agilent Technologies, Palo Alto, CA, USA). The carrier gas 
used was helium with a flow rate of $1 \mathrm{ml} \mathrm{min}^{-1}$. The injection volume was $1 \mu \mathrm{l}$. The chromatographic conditions were: injector temperature: $250{ }^{\circ} \mathrm{C}$; detector temperature: $300{ }^{\circ} \mathrm{C}$; Oven programming: initial oven temperature 50 ${ }^{\circ} \mathrm{C}$ with a temperature increase rate of $30^{\circ} \mathrm{C} \min ^{-1}$ until reaching $275^{\circ} \mathrm{C}$.

\subsection{Colorimetric determination of total phenols}

Phenolic compounds extraction was carried out according to the method described by Ben Moumen et al. [14] using a methanol/water mixture $(80 / 20 ; \mathrm{v} / \mathrm{v})$ as extraction solvent. The total phenol content was determined by the Folin-Ciocalteu method at $750 \mathrm{~nm}$ using a UV spectrophotometer (RAYLEIGH UV1800, UV-Visible) according to the procedure described by Ben Moumen et al. [14] using caffeic acid (Sigma-Aldrich, St. Louis, MO, USA) as external standard.

\subsection{Analysis of phenolic compounds by HPLC-DAD}

Phenolic compounds' separation was carried out on a Zorbax XDB-C18 column $(150 \mathrm{~mm} \times 4.6 \mathrm{~mm}, 3.5 \mu \mathrm{m}$ particle size; Agilent Technologies, Palo Alto, CA, USA) by HPLC (Agilent Technology series 1100 system, Palo Alto, CA, USA) equipped with a diode array detector. The solvent system used was a gradient of A (water $+0.5 \%$ formic acid) and B (methanol $+0.5 \%$ formic acid) according to the method described by Bakhouche et al. [16]. The flow rate was $1 \mathrm{ml} \mathrm{min}^{-1}$. Detection was made at 254, 280, 320 and $340 \mathrm{~nm}$ and the identification of phenolic compounds was carried out at $280 \mathrm{~nm}$. Hydroxytyrosol, tyrosol, vanillin, apigenin, luteolin and vanillic, $p$-coumaric and cinnamic acids were identified and quantified by external standardization with commercial standards (SigmaAldrich, St. Louis, MO, USA). The identification and quantification of decarboxymethyl ligstroside aglycone and decarboxymethyl oleuropein aglycone were performed by comparing their retention time with those published by Bakhouche et al. [16] and the use of response factors determined by Mateos et al. [17].

\subsection{Tocopherol analysis}

Tocopherols were evaluated according to the AOCS method Ce 8-89 [18] on an HPLC (Agilent technologies series 1200 system, Palo Alto, CA, USA) equipped with UV detector. The separation was carried out on a column of silica Uptisphère $120 \AA ̊$ $\mathrm{NH}_{2}(150 \mathrm{~mm} \times 3 \mathrm{~mm}, 5 \mu \mathrm{m}$ particle size; Interchim, Montlucon, France) which was eluted with a mobile phase composed of n-hexane/2-propanol $(99 / 1 ; \mathrm{v} / \mathrm{v})$ at a flow rate of $1 \mathrm{ml} \mathrm{min}$. The identification was performed using commercial tocopherol standards $(\alpha, \beta, \gamma$ and $\delta$-tocopherols; Sigma-Aldrich, St. Louis, USA) at $292 \mathrm{~nm}$.

\subsection{Statistical analysis}

The results presented in this work are the means of analyses carried out in triplicate with the corresponding standard deviations (for each parameter: 3 determinations $\times 3$ samples $\times 2$ crop seasons $=18$ ). One-way ANOVA and Duncan's Post-hoc tests were used to determine significant differences between means. The significant difference threshold was set at 5\%. The principal component analysis was performed on the dataset to determine the variables that differentiate the olive oil samples by cultivar. The applications of these statistical analyses were carried out using the software for Windows: IBM Statistical Package for the Social Sciences (IBM SPSS. 20).

\section{Results and discussion}

\subsection{Quality parameters and oxidative stability}

The physicochemical quality indices of olive oils from the studied cultivars (Table 1) show values that comply with the standards set by the International Olive Council [19] for extra VOO category (acidity $\leq 0.8 \%$, peroxide value $\leq 20$ meq $\mathrm{O}_{2} \mathrm{~kg}^{-1}, \mathrm{~K}_{232} \leq 2.5$ and $\mathrm{K}_{270} \leq 0.22$ ). The low values of these parameters found in all the analyzed oils result in a good quality of the olive oils obtained from the fresh and healthy olives harvested at the point of 
optimal maturation and followed by an immediate extraction without storage. However, significant differences $(p<0.05)$ between cultivars were observed for peroxide index and UV absorbance. Several studies have shown that the varietal factor had no significant influence on these physicochemical parameters. These indices can be influenced by factors that cause damage to olive fruit [12].

Oxidative stability is an important parameter that contributes to the assessment of olive oil quality. The study of oxidative stability of the analyzed oils, measured by the Rancimat test at $100{ }^{\circ} \mathrm{C}$, shows that this parameter depends on the variety $(p<0.05)$. Table 1 shows that Koroneiki oil has the highest induction time with an average of 98.64hours followed by Arbosana oil (74.49 h) and Arbequina oil (52.07 h). The difference observed between the studied VOOs is due to the variation of their constituents. In fact, several studies on the contribution of the constituents of olive oil to oxidative stability have concluded that the resistance of olive oil to oxidation is related to its monounsaturated and polyunsaturated fatty acid contents, and natural antioxidants, mainly the phenolic compounds and tocopherols $[5,21]$. Our results of oxidative stability are higher than those reported by Allalout et al. [21], using an air flow of $10 \mathrm{~L} \mathrm{~h}^{-1}$ in the same experimental conditions, for virgin olive oils of the same varieties cultivated in Tunisia.

Table 1. Standard quality parameters and oxidative stability of Arbequina, Arbosana and Koroneiki virgin olive oils.

\begin{tabular}{llll}
\hline \multirow{2}{*}{ Quality parameters } & \multicolumn{2}{l}{ Olive varieties } & Koroneiki \\
\cline { 2 - 4 } & Arbequina & Arbosana & $0.44 \pm 0.15^{\mathrm{a}}$ \\
\hline Free acidity $(\% \mathrm{C} 18: 1)$ & $0.35 \pm 0.11^{\mathrm{a}}$ & $0.37 \pm 0.18^{\mathrm{a}}$ & $9.77 \pm 0.99^{\mathrm{c}}$ \\
Peroxide value (meq $\left.\mathrm{O}_{2} \mathrm{~kg}^{-1}\right)$ & $7.29 \pm 1.06^{\mathrm{a}}$ & $8.30 \pm 0.96^{\mathrm{b}}$ & $1.56 \pm 0.09^{\mathrm{a}}$ \\
$\mathrm{K}_{232}$ & $1.54 \pm 0.15^{\mathrm{a}}$ & $1.64 \pm 0.09^{\mathrm{b}}$ & $0.14 \pm 0.01^{\mathrm{c}}$ \\
$\mathrm{K}_{270}$ & $0.09 \pm 0.01^{\mathrm{a}}$ & $0.12 \pm 0.00^{\mathrm{b}}$ & $98.64 \pm 4.01^{\mathrm{c}}$ \\
Oxidative stability (hours) & $52.07 \pm 2.01^{\mathrm{a}}$ & $74.49 \pm 4.58^{\mathrm{b}}$ & \\
\hline
\end{tabular}

Significant differences $(p<0.05)$ in the same line are indicated by different letters $(\mathrm{a}-\mathrm{c})$.

\subsection{Fatty acid and triacylglycerol compositions}

The results of the fatty acid analysis presented in Table 2 reveal the presence of ten fatty acid compounds in the analyzed oil samples. The major fatty acid is oleic acid, followed by palmitic and linoleic acids. Significant differences between the varieties were observed on all the identified compounds $(p<0.05)$. The oils of Koroneiki and Arbosana varieties are characterized by high levels of oleic acid (76.70 and $74.39 \%$, respectively) compared to that of Arbequina olive oil estimated at $67.70 \%$. Thus, Koroneiki and Arbosana oils are characterized by low proportions of linoleic acid (5.76 and 6.03\%, respectively) compared to that of Arbequina oil estimated at $10.40 \%$. Concerning palmitic acid, Koroneiki and Arbosana varieties produce oils with relatively low levels, 13.89 and $14.28 \%$ respectively, compared to Arbequina variety (16.69\%). Other fatty acids, including palmitoleic, heptadecanoic, heptadecenoic, stearic, linolenic, arachidic and gadoleic acids vary from one variety to another and they are present at low proportions.

The proportions of saturated (SFA), monounsaturated (MUFA) and polyunsaturated fatty acids (PUFA) were also evaluated (Table 2). Koroneiki oil has the highest proportion of MUFA (77.90\%) and the lowest level of PUFA $(6.40 \%)$, because of its high oleic acid content and low linoleic acid content that respectively represent the main fatty acids of these two fractions. In contrast, Arbequina oil has the highest PUFA level (10.95\%) and the lowest proportion in MUFA (69.98\%). Arbequina oil has also the highest value of SFA (19.00\%) due to its high palmitic acid content which is the major fatty acid of this fraction, while Koroneiki oil has the lowest value (15.62\%).

The major fatty acids' composition of VOOs from Spanish varieties (Arbequina and Arbosana) introduced in north-eastern Morocco (Table 2) is different from those observed in these same varieties cultivated in their original site [22] and Tunisia [21] under irrigated high-density planting system. Arbequina and Arbosana, when grown in north-eastern Morocco, produce oils with lower levels of linoleic acid than those of their site of origin (11.10 and $7.90 \%$, respectively) and in Tunisia (12.93 and 12.09\%, respectively). However, the oils produced in Morocco have oleic acid proportions close to those obtained in Spain (69.40 and 73.00\%, respectively) and much higher than those obtained in Tunisia (58.82 and 64.79\%, respectively). Similarly, Arbequina and Arbosana grown in Morocco 
produce oils with higher percentages of palmitic acid, compared to their original site (14.50 and $13.60 \%$, respectively) and lower percentages compared to the oils produced in Tunisia (17.57 and $17.78 \%$, respectively).

Koroneiki olive oil has a comparable oleic acid composition between north-eastern Morocco and northern Tunisia (75.53\%), where the cultivar is grown under irrigated high-density planting system [21], and in its original growing area $(76.22 \%)$, even when the variety is conducted in rainfed cultural system [23]. On the other hand, palmitic and linoleic acid proportions vary from one region to another. Koroneiki grown in Morocco produces an oil with a higher palmitic acid and low linoleic acid content than in its site of origin (10.36 and 8.34\%, respectively) and Tunisia (11.65 and 8.56\%, respectively) which is in favor of its better oxidation stability and therefore a better aptitude for preservation.

The triacylglycerol composition of the analyzed VOOs is shown in Table 2. Nine molecular species of triacylglycerols have been identified. All samples have three molecular species of major triacylglycerols: triolein (OOO), palmityldiolein (POO) and linoleyldiolein (LOO). These results are in accordance with those of other authors [24]. Additionally, these three major molecular species account for more than $76 \%$ of the identified total triacylglycerols. They are accompanied with lower percentages of linoleylpalmitylolein (LPO) and stearyldiolein (SOO) as well as minor triacyglycerols, including LOL, LPL, POP and POLn. As shown in Table 2, the proportions of triacylglycerols vary significantly between oil samples $(p<0.05)$, as is the case with fatty acids. The average value of OOO follows the same variations as oleic acid with percentages ranging from $34.52 \%$ for Arbequina oil to $48.55 \%$ for Koroneiki oil. Similarly, a wide variation in the proportions of POO and LOO was observed. Arbequina oil has the lowest percentage of POO $(26.18 \%)$ and the highest percentage of LOO $(15.59 \%)$, while that of Arbosana oil is the highest in POO (28.70\%) and that of Koroneiki oil is the lowest in LOO (10.20\%).

Table 2. Fatty acid and triacylglycerol compositions of Arbequina, Arbosana and Koroneiki monovarietal virgin olive oils.

\begin{tabular}{|c|c|c|c|}
\hline \multirow{2}{*}{ Fatty acids \& triacylglycerols (\%) } & \multicolumn{3}{|l|}{ Olive varieties } \\
\hline & Arbequina & Arbequina & Arbequina \\
\hline C16:0 & $16.69 \pm 0.74^{b}$ & $14.28 \pm 0.61^{\mathrm{a}}$ & $13.89 \pm 1.88^{\mathrm{a}}$ \\
\hline C16:1 & $1.77 \pm 0.14^{\mathrm{c}}$ & $1.31 \pm 0.05^{\mathrm{b}}$ & $0.95 \pm 0.30^{\mathrm{a}}$ \\
\hline $\mathrm{C} 17: 0$ & $0.11 \pm 0.01^{\mathrm{b}}$ & $0.16 \pm 0.01^{\mathrm{c}}$ & $0.02 \pm 0.02^{\mathrm{a}}$ \\
\hline $\mathrm{C} 17: 1$ & $0.23 \pm 0.03^{\mathrm{b}}$ & $0.35 \pm 0.01^{\mathrm{c}}$ & $0.04 \pm 0.04^{\mathrm{a}}$ \\
\hline C18:0 & $1.83 \pm 0.28^{\mathrm{b}}$ & $2.06 \pm 0.22^{\mathrm{b}}$ & $1.39 \pm 0.92^{\mathrm{a}}$ \\
\hline C18:1 & $67.70 \pm 2.32^{\mathrm{a}}$ & $74.39 \pm 1.38^{\mathrm{b}}$ & $76.70 \pm 0.61^{\mathrm{c}}$ \\
\hline C18:2 & $10.40 \pm 2.25^{\mathrm{a}}$ & $6.03 \pm 0.38^{\mathrm{b}}$ & $5.76 \pm 0.52^{\mathrm{b}}$ \\
\hline C18:3 & $0.55 \pm 0.01^{\mathrm{a}}$ & $0.65 \pm 0.01^{\mathrm{b}}$ & $0.64 \pm 0.03^{\mathrm{b}}$ \\
\hline $\mathrm{C} 20: 0$ & $0.36 \pm 0.09^{\mathrm{a}}$ & $0.40 \pm 0.04^{\mathrm{b}}$ & $0.32 \pm 0.09^{\mathrm{a}}$ \\
\hline $\mathrm{C} 20: 1$ & $0.29 \pm 0.05^{\mathrm{b}}$ & $0.28 \pm 0.02^{\mathrm{b}}$ & $0.22 \pm 0.05^{\mathrm{a}}$ \\
\hline$\Sigma$ SFA & $19.00 \pm 0.69^{\mathrm{c}}$ & $16.90 \pm 0.83^{b}$ & $15.62 \pm 0.88^{\mathrm{a}}$ \\
\hline$\Sigma$ MUFA & $69.98 \pm 2.35^{\mathrm{a}}$ & $76.33 \pm 1.29^{b}$ & $77.90 \pm 0.49^{\mathrm{c}}$ \\
\hline$\Sigma$ PUFA & $10.95 \pm 2.26^{\mathrm{b}}$ & $6.68 \pm 0.39^{\mathrm{a}}$ & $6.40 \pm 0.52^{\mathrm{a}}$ \\
\hline LOL & $2.68 \pm 0.56^{\mathrm{b}}$ & $1.06 \pm 0.15^{\mathrm{a}}$ & $1.22 \pm 0.13^{\mathrm{a}}$ \\
\hline LPL & $1.64 \pm 0.19^{b}$ & $1.39 \pm 0.16^{\mathrm{a}}$ & $1.3 \pm 0.11^{\mathrm{a}}$ \\
\hline POLn & $1.26 \pm 0.05^{\mathrm{b}}$ & $0.70 \pm 0.10^{\mathrm{a}}$ & $0.66 \pm 0.13^{\mathrm{a}}$ \\
\hline LOO & $15.59 \pm 0.76^{\mathrm{b}}$ & $10.30 \pm 0.53^{\mathrm{a}}$ & $10.20 \pm 0.40^{\mathrm{a}}$ \\
\hline LPO & $9.50 \pm 1.67^{\mathrm{c}}$ & $5.49 \pm 0.65^{\mathrm{b}}$ & $4.28 \pm 0.16^{\mathrm{a}}$ \\
\hline $\mathrm{OOO}$ & $34.52 \pm 3.10^{\mathrm{a}}$ & $42.65 \pm 2.37^{\mathrm{b}}$ & $48.55 \pm 0.56^{\mathrm{c}}$ \\
\hline POO & $26.18 \pm 0.35^{\mathrm{a}}$ & $28.70 \pm 1.30^{\mathrm{b}}$ & $26.42 \pm 0.18^{\mathrm{a}}$ \\
\hline POP & $1.39 \pm 0.14^{\mathrm{c}}$ & $1.07 \pm 0.38^{\mathrm{a}}$ & $0.66 \pm 0.42^{\mathrm{a}}$ \\
\hline SOO & $4.05 \pm 0.30^{\mathrm{b}}$ & $3.93 \pm 0.21^{\mathrm{b}}$ & $10 \pm 0.55^{\mathrm{a}}$ \\
\hline
\end{tabular}

Significant differences $(p<0.05)$ in the same line are indicated by different letters (a-c). SFA, Saturated fatty acids; MUFA, Monounsaturated fatty acids; PUFA, Polyunsaturated fatty acids; L, Linoleyl; Ln, Linolenyl; O, Oleyl; P, Palmityl; S, Stearyl. 


\subsection{Phytosterols}

The composition of the sterol fraction of olive oil is a very useful parameter for detecting forgery. According to the results presented in Table 3, the total phytosterol contents of the three studied varieties are consistent with those indicated by the International Olive Council's standard [19]. They are higher than $1000 \mathrm{mg} \mathrm{kg}^{-1}$ set by the standard for extra VOO category. Arbequina oil has the highest average content with $1970.83 \mathrm{mg} \mathrm{kg}^{-1}$, followed by Arbosana and Koroneiki oils (1945.51 and $1598.16 \mathrm{mg} \mathrm{kg}^{-1}$, respectively). Additionally, ANOVA statistical analysis shows that variation in total phytosterol content is strongly influenced by the cultivar $(p<0.05)$.

The sterol profile of the analyzed olive oils is characterized by the predominance of $\beta$-sitosterol followed by $\Delta^{5}$ avenasterol, the contents of which vary according to the variety $(p<0.05)$. The proportions of $\beta$-sitosterol follow the same variations as total phytosterols with percentages that fluctuate between 74.40 and $80.70 \%$. On the other hand, $\Delta^{5}$-avenasterol is negatively correlated with $\beta$-sitosterol whose content ranges between 10.68 and $16.74 \%$.

Other sterol compounds have been identified in significant amounts. Namely, stigmasterol and campesterol (Table 3). The oil from Arbosana variety recorded the highest proportions of stigmasterol and campesterol ( 0.77 and $3.40 \%$, respectively). While the lowest values were recorded in Koroneiki oil ( 0.40 and $2.54 \%$, respectively).

Cholesterol, 24-methylene cholesterol, clerosterol, $\Delta^{5,24}$-stigmastadienol, $\Delta^{7}$-stigmastenol, $\Delta^{7}$-avenasterol and erythrodiol are present in all studied varieties but with low proportions. The sum of their contents does not exceed $6 \%$ of total phytosterols. Arbequina oil is still characterized by high levels of cholesterol, clerosterol and $\Delta^{7}$ avenasterol $\left(0.18,1.17\right.$ and $0.96 \%$, respectively), while the highest proportions of 24-methylene cholesterol and $\Delta^{7}$ stigmastenol were recorded in Koroneiki oil ( 0.42 and $0.41 \%$, respectively).

Table 3. Phytosterol compositions of Arbequina, Arbosana and Koroneiki monovarietal virgin olive oils.

\begin{tabular}{|c|c|c|c|}
\hline \multirow{2}{*}{ Phytosterols (\% of total phytosterols) } & \multicolumn{3}{|l|}{ Olive varieties } \\
\hline & Arbequina & Arbequina & Arbequina \\
\hline Cholesterol & $0.18 \pm 0.01^{\mathrm{c}}$ & $0.12 \pm 0.00^{\mathrm{a}}$ & $0.16 \pm 0.01^{\mathrm{b}}$ \\
\hline 24-Methylene cholesterol & $0.38 \pm 0.02^{\mathrm{b}}$ & $0.18 \pm 0.01^{\mathrm{a}}$ & $0.42 \pm 0.01^{\mathrm{c}}$ \\
\hline Campesterol & $2.89 \pm 0.07^{\mathrm{b}}$ & $3.40 \pm 0.10^{\mathrm{c}}$ & $2.54 \pm 0.11^{\mathrm{a}}$ \\
\hline Stigmasterol & $0.74 \pm 0.02^{\mathrm{b}}$ & $0.77 \pm 0.01^{\mathrm{c}}$ & $0.40 \pm 0.01^{\mathrm{a}}$ \\
\hline Clerosterol & $1.17 \pm 0.08^{\mathrm{c}}$ & $1.04 \pm 0.02^{\mathrm{b}}$ & $0.96 \pm 0.16^{\mathrm{a}}$ \\
\hline$\beta$-Sitosterol & $79.04 \pm 0.77^{\mathrm{c}}$ & $77.42 \pm 0.35^{\mathrm{b}}$ & $75.72 \pm 0.64^{\mathrm{a}}$ \\
\hline$\Delta^{5}$-Avenasterol & $12.32 \pm 0.79^{\mathrm{a}}$ & $13.52 \pm 0.25^{\mathrm{b}}$ & $15.90 \pm 0.43^{\mathrm{c}}$ \\
\hline$\Delta^{5,24}$-Stigmastadienol & $0.66 \pm 0.01^{\mathrm{b}}$ & $1.07 \pm 0.05^{\mathrm{c}}$ & $0.57 \pm 0.01^{\mathrm{a}}$ \\
\hline$\Delta^{7}$-Stigmastenol & $0.39 \pm 0.01^{\mathrm{b}}$ & $0.27 \pm 0.01^{\mathrm{a}}$ & $0.41 \pm 0.03^{\mathrm{c}}$ \\
\hline$\Delta^{7}$-Avenasterol & $0.96 \pm 0.05^{\mathrm{c}}$ & $0.68 \pm 0.02^{\mathrm{a}}$ & $0.73 \pm 0.05^{\mathrm{b}}$ \\
\hline Erythrodiol & $1.28 \pm 0.02^{\mathrm{a}}$ & $1.51 \pm 0.05^{\mathrm{b}}$ & $2.18 \pm 0.24^{\mathrm{c}}$ \\
\hline Total phytosterols ( $\left.\mathrm{mg} \mathrm{kg}^{-1}\right)$ & $1970.83 \pm 9.36^{\mathrm{c}}$ & $1945.51 \pm 21.11^{\mathrm{b}}$ & $1598.16 \pm 38.15^{\mathrm{a}}$ \\
\hline
\end{tabular}

Significant differences $(p<0.05)$ in the same line are indicated by different letters $(\mathrm{a}-\mathrm{c})$.

\subsection{Phenolic compounds}

Phenolic compounds are considered as the main antioxidants of VOO. These compounds are also responsible for some key sensory properties of olive oil, attributing to it a bitter taste and pungency [25]. The evaluation of the total content of phenolic compounds in VOO samples is the first step in the characterization of these compounds. From Table 4, we note that the phenol content is significantly influenced by the cultivar $(p<0.05)$. Koroneiki oil is the richest in total phenols with an average content of $529.99 \mathrm{mg} \mathrm{kg}^{-1}$, followed by Arbosana oil (433.22 $\left.\mathrm{mg} \mathrm{kg}^{-1}\right)$ and Arbequina oil (263.89 $\mathrm{mg} \mathrm{kg}^{-1}$ ). The total phenol richness of Arbequina and Arbosana varieties grown in northeastern Morocco does not display the same trends compared to the results found at their original site. In fact, the total phenol contents are either higher than the results published by Hermoso et al. [22] on the same varieties (234 and $343 \mathrm{ppm}$, respectively) cultivated in Spain under the same planting system. Also, the results obtained in Morocco are significantly higher compared to the results reported in Tunisia (108 and $137 \mathrm{mg} \mathrm{kg}^{-1}$, respectively) [21]. Koroneiki oil produced in Morocco has a high phenol content compared to that obtained in Tunisia (236 mg 
$\mathrm{kg}^{-1}$ ) [21]. On the other hand, it showed a small amount of total phenols when it was grown in Morocco (Table 4) compared to its original site $\left(583 \mathrm{mg} \mathrm{kg}^{-1}\right)$ where it is conducted in a rainfed cultural system [26]. This difference is due to the culture system that differs between the two sites. In addition, the total phenol content is influenced by other factors such as climate, location, ripening degree and processing methods [5].

To complete the study of phenolic compounds, we sought to determine the molecular composition of these compounds in the studied olive oils. As shown in Table 4, eleven phenolic compounds were identified and quantified in all hydro-methanolic extracts of the analyzed oil samples. The statistical analysis of variances shows that the contents of the determined phenolic compounds vary according to the cultivar $(p<0.05)$. The results also show that decarboxymethyl oleuropein aglycone (DOA) and decarboxymethyl ligstroside aglycone (DLA), which constitute the fraction of secoiridoid derivatives, are the major identified compounds in all the analyzed oils. VOOs of Spanish varieties are characterized by low amounts of DOA and DLA, respectively between 94.84 (Arbequina) and $140.85 \mathrm{mg} \mathrm{kg}^{-1}$ (Arbosana) and between 114.97 (Arbequina) and $164.21 \mathrm{mg} \mathrm{kg}^{-1}$ (Arbosana), compared to those of Koroneiki oil (164.86 and $180.55 \mathrm{mg} \mathrm{kg}^{-1}$, respectively).

As for phenolic alcohols, this group is composed of hydroxytyrosol and tyrosol. Koroneiki oil has the highest averages (15.55 and $7.17 \mathrm{mg} \mathrm{kg}^{-1}$, respectively), while the lowest values are recorded in Arbequina oil (2.29 and $2.23 \mathrm{mg} \mathrm{kg}^{-1}$, respectively). Pinoresinol, which is a lignan, was also detected at considerable concentrations in the analyzed samples. Arbosana oil has the highest content $\left(7.26 \mathrm{mg} \mathrm{kg}^{-1}\right)$, followed by Arbequina and Koroneiki oils ( 4.55 and $4.33 \mathrm{mg} \mathrm{kg}^{-1}$, respectively). Flavonoids are also part of the phenolic compounds present in the analyzed oils. The concentration of apigenin varies between 3.06 (Arbequina) and $8.49 \mathrm{mg} \mathrm{kg}^{-1}$ (Arbosana). Similarly, the content of luteolin is variable. Arbosana oil has the highest content $\left(6.96 \mathrm{mg} \mathrm{kg}^{-1}\right)$, while Arbequina and Koroneiki oils have low levels (5.96 and $6.00 \mathrm{mg} \mathrm{kg}^{-1}$, respectively).

On the other hand, the analysis of phenolic compounds also reveals the presence of the fraction of phenolic acids in the analyzed oils, but at very low levels (Table 4). It consists of vanillic, $p$-coumaric and cinnamic acids. Their concentrations vary slightly according to the studied oils. $p$-coumaric acid varies in a range of $0.06-0.31 \mathrm{mg} \mathrm{kg}^{-1}$, vanillic acid 0.25-0.65 $\mathrm{mg} \mathrm{kg}^{-1}$ and cinnamic acid $0.11-0.70 \mathrm{mg} \mathrm{kg}^{-1}$.

Table 4. Phenolic compounds composition of Arbequina, Arbosana and Koroneiki monovarietal virgin olive oils.

\begin{tabular}{llll}
\hline \multirow{2}{*}{ Phenolic compounds $\left(\mathrm{mg} \mathrm{kg}^{-1}\right)$} & Olive varieties & & Arbequina \\
\cline { 2 - 4 } & Arbequina & $10.42 \pm 0.69^{\mathrm{b}}$ & $15.55 \pm 1.43^{\mathrm{c}}$ \\
\hline Hydroxytyrosol & $2.29 \pm 0.36^{\mathrm{a}}$ & $4.56 \pm 0.15^{\mathrm{b}}$ & $7.17 \pm 0.24^{\mathrm{c}}$ \\
Tyrosol & $2.23 \pm 0.76^{\mathrm{a}}$ & $0.31 \pm 0.06^{\mathrm{a}}$ & $0.52 \pm 0.10^{\mathrm{c}}$ \\
Vanillic acid & $0.47 \pm 0.06^{\mathrm{b}}$ & $0.36 \pm 0.08^{\mathrm{b}}$ & $0.22 \pm 0.04^{\mathrm{a}}$ \\
Vanillin & $0.34 \pm 0.12^{\mathrm{b}}$ & $0.07 \pm 0.01^{\mathrm{a}}$ & $0.14 \pm 0.02^{\mathrm{b}}$ \\
p-Coumaric acid & $0.20 \pm 0.08^{\mathrm{c}}$ & $140.85 \pm 12.79^{\mathrm{b}}$ & $164.86 \pm 18.70^{\mathrm{c}}$ \\
DOA & $94.84 \pm 9.80^{\mathrm{a}}$ & $164.21 \pm 7.70^{\mathrm{b}}$ & $180.55 \pm 15.59^{\mathrm{c}}$ \\
DLA & $114.97 \pm 7.18^{\mathrm{a}}$ & $7.26 \pm 0.20^{\mathrm{b}}$ & $4.33 \pm 0.48^{\mathrm{a}}$ \\
Pinoresinol & $4.55 \pm 0.70^{\mathrm{a}}$ & $0.21 \pm 0.04^{\mathrm{b}}$ & $0.62 \pm 0.07^{\mathrm{c}}$ \\
Cinnamic acid & $0.15 \pm 0.04^{\mathrm{a}}$ & $6.96 \pm 0.29^{\mathrm{b}}$ & $6.00 \pm 0.62^{\mathrm{a}}$ \\
Luteolin & $5.96 \pm 0.96^{\mathrm{a}}$ & $8.49 \pm 0.96^{\mathrm{c}}$ & $3.72 \pm 0.19^{\mathrm{b}}$ \\
Apigenin & $3.06 \pm 0.28^{\mathrm{a}}$ & $433.22 \pm 23.34^{\mathrm{b}}$ & $529.99 \pm 37.65^{\mathrm{c}}$ \\
Total phenols* & $263.89 \pm 23.66^{\mathrm{a}}$ & & \\
\hline
\end{tabular}

Significant differences $(p<0.05)$ in the same line are indicated by different letters $(\mathrm{a}-\mathrm{c})$. DOA, Decarboxymethyl oleuropein aglycone; DLA, Decarboxymethyl ligstroside aglycone. ${ }^{*}$ Concentrations of total phenols expressed as $\mathrm{mg}$ of caffeic acid per kg of oil (colorimetric method).

\subsection{Tocopherols}

In addition to their vitamin property, tocopherols are important compounds of olive oil because of their role, along with phenolic compounds, in the preservation of free radicals. The determination of the total content of tocopherols of the oil samples (Table 5) shows a clear influence of the varietal factor on the tocopherol content ( $p<$ 0.05). The highest average total tocopherol content was observed in Arbosana oil (449.27 $\mathrm{mg} \mathrm{kg}^{-1}$ ), while Arbequina oil had the lowest value (333.12 $\left.\mathrm{mg} \mathrm{kg}^{-1}\right)$. 
The separation and identification of tocopherols by HPLC reveal the presence of three homologs: $\alpha, \beta$ and $\gamma$ tocopherols. Table 5 shows that $\alpha$-tocopherol, which has the highest vitamin activity, is present in a dominant proportion (over $96 \%$ of total tocopherols). Arbosana oil has the highest concentration (439 $\left.\mathrm{mg} \mathrm{kg}^{-1}\right)$. In comparison with $\alpha$-tocopherol, the contents of oil samples in $\beta$ and $\gamma$-tocopherols are very low. They are respectively between 1.68 (Arbequina) and $4.12 \mathrm{mg} \mathrm{kg}^{-1}$ (Koroneiki), and between 2.61 (Arbequina) and $8.71 \mathrm{mg} \mathrm{kg}^{-1}$ (Koroneiki).

Table 5. Tocopherols composition of Arbequina, Arbosana and Koroneiki monovarietal virgin olive oils.

\begin{tabular}{llll}
\hline \multirow{2}{*}{ Tocopherols $\left(\mathrm{mg} \mathrm{kg}^{-1}\right)$} & Olive varieties & & \\
\cline { 2 - 4 } & Arbequina & Arbequina & Arbequina \\
\hline$\alpha$-Tocopherol & $328.83 \pm 11.58^{\mathrm{a}}$ & $439.54 \pm 23.31^{\mathrm{c}}$ & $350.12 \pm 7.89^{\mathrm{b}}$ \\
$\beta$-Tocopherol & $1.68 \pm 0.17^{\mathrm{a}}$ & $3.25 \pm 1.52^{\mathrm{b}}$ & $4.12 \pm 0.71^{\mathrm{c}}$ \\
$\gamma$-Tocopherol & $2.61 \pm 0.59^{\mathrm{a}}$ & $6.48 \pm 0.23^{\mathrm{b}}$ & $8.71 \pm 0.80^{\mathrm{c}}$ \\
Total tocopherols & $333.12 \pm 11.80^{\mathrm{a}}$ & $449.27 \pm 24.57^{\mathrm{c}}$ & $362.95 \pm 7.61^{\mathrm{b}}$ \\
\hline
\end{tabular}

Significant differences $(p<0.05)$ in the same line are indicated by different letters $(a-c)$.

\subsection{Multivariate analysis}

The highlighting of the variation in the composition of olive oils of the studied varieties had led us to perform a principal component analysis (PCA). The results allowed us to isolate six factors (F) explaining $100 \%$ of the analyzed variances. The first three factors accounted for $73.83 \%$ of the total information. The most contributor F1 parameters are: total phenols, DOA, hydroxytyrosol, DLA, oxidative stability, $\beta$-tocopherol, tyrosol, C16:1, LOO, $\mathrm{C} 18: 3 \mathrm{n} 3$, OOO, SOO, $\Delta^{5}$-avenasterol, cinnamic acid, C16:0, C18:1, C18:3, total phytosterols, $\Delta^{7}$-avenasterol, LPO and POLn. The 24-methylene cholesterol, POO, $\Delta^{7}$-stigmastenol, $\Delta^{5,24}$-stigmastadienol, pinoresinol, apigenin, campesterol, total tocopherols, cholesterol, vanillic acid, C17:1 and C17:0 lend their variance to F2. Cultivars' projection on the factorial map allows a clear separation between the analyzed samples (Figure 2).

According to the three-dimensional representation of the first three factors, Arbequina oil has a profile far removed from the other varieties. Arbosana and Koroneiki oils are more correlated with F1 than the Arbequina oil. This means that Arbequina variety is very different from the other varieties, since the first axis is the one that best separates the points because it explains $43.11 \%$ of the information. In addition, Arbosana is opposite of the Koroneiki variety compared to F2.

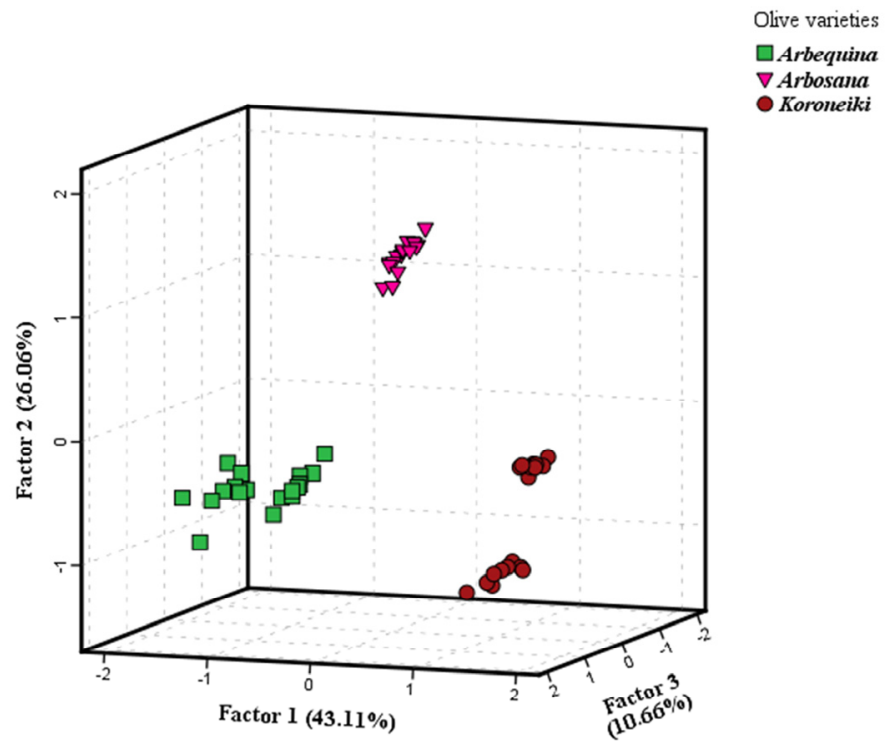

Fig. 2 Three-dimensional principal component analysis plot of all collected data obtained from Arbequina, Arbosana and Koroneiki monovarietal virgin olive oils. 


\section{Conclusion}

The analysis of virgin olive oils of Spanish (Arbequina and Arbosana) and Greek (Koroneiki) varieties grown in north-eastern Morocco under irrigated super-high-density planting system has shown that the values of quality parameters fall within the limits recommended by the International Olive Council for extra virgin olive oil category.

Spanish varieties when grown in Morocco produced oils different from those obtained in their original site and in Tunisia, in terms of major fatty acids and total phenols. Arbequina and Arbosana when grown in Morocco produced oils with low levels of linoleic acid compared to their original sites and in Tunisia. However, the oils produced in Morocco had similar oleic acid proportions to those obtained in Spain and much higher than those obtained in Tunisia. The total phenol contents were also higher than those obtained in their original growing area and in Tunisia. On the other hand, Koroneiki variety produced oil with very close predominant fatty acids to that obtained in its original site and in Tunisia. Moreover, it showed a small amount in total phenols when it is cultivated in Morocco compared to their original growing area.

\section{References}

[1]. R.W. Owen, W. Mier, A. Giacosa, W.E. Hull, B. Spiegelhalder, H. Bartsch. Clin. Chem. 46 (2000) 976-988.

[2]. C. Soler-Rivas, J.C. Espín, H.J. Wichers. J. Sci. Food Agric. 80 (2000) 1013-1023.

[3]. F. Gutiérrez-Rosales, J. Rios, M.L. Gomez-Rey. J. Agric. Food Chem. 51 (2003) 6021-6025.

[4]. F. Mansouri, A. Ben Moumen, G. Richard, M. L. Fauconnier, M. Sindic, H. Serghini Caid, A. Elamrani. Riv. Ital. Sostanze Gr. 93 (2016) 21-30.

[5]. M.P. Aguilera, G. Beltrán, D. Ortega, A. Fernández, A. Jiménez, M. Uceda. Food Chem. 89 (2005) 387-391.

[6]. M. Richelle, M. Enslen, C. Hager, M. Groux, I. Tavazzi, J.P. Godin, A. Berger, S. Métairon, S. Quaile, C. Piguet-Welsch. Am. J. Clin. Nutr. 80 (2004) 171-177.

[7]. J. Velasco, C. Dobarganes. Eur. J. Lipid Sci. Technol. 104 (2002) 661-676.

[8]. F. Mansouri, A. Ben Moumen, K. Belhaj, M.L. Fauconnier, M. Sindic, H. Serghini Caid, A. Elamrani. Emir. J. Food Agr. 30 (2018) 549-562.

[9]. M.P. Romero, M.J. Tovar, T. Ramo, M.J. Motilva. J. Am. Oil. Chem. Soc. 80 (2003) 423-430.

[10]. J.R. Morelló, M.J. Motilva, M.J. Tovar, M.P. Romero. Food Chem. 85 (2004) 357-364.

[11]. F. Mansouri, A. Ben Moumen, G. Richard, M.L. Fauconnier, M. Sindic, H. Serghini Caid, A. Elamrani. J. Mater. Environ. Sci. 6 (2015) 2322-2329.

[12]. S. Camposeo, A. Godini. Advances in horticultural science 24 (2010) 16-20.

[13]. European Union Commission Regulation EEC/2568/91. Offic. J. Eur. Commun. L248 (1991) 30.

[14]. A. Ben Moumen, F. Mansouri, G. Richard, M. Abid, M.L. Fauconnier, M. Sindic, A. Elamrani, H. Serghini Caid. Inter. Food Sci. Tech. 50 (2015) 804-810.

[15]. A. Ben Moumen, F. Mansouri, G. Richard, M.L. Fauconnier, M. Sindic, A. Nabloussi, A. Elamrani, H. Serghini Caid. Inter. Food Sci. Tech. 50 (2015) 2264-2270.

[16]. A. Bakhouche, J. Lozano-Sánchez, R. Beltrán-Debón, J. Joven, A. Segura-Carretero, A. Fernández-Gutiérrez. Food Res. Int.50 (2013) 401-408.

[17]. R. Mateos, J.L. Espartero, M. Trujillo, J. Rios, M. León-Camacho, F. Alcudia, A. Cert. J. Agric. Food. Chem. 49 (2001) 2185-2192.

[18]. American Oil Chemists Society. Offic Method Ce 8-89 (1989).

[19]. International Olive Council, COI/T.15/NC 3/Rév. 8 Febr (2015).

[20]. E. Khlil, F. Mansouri, A. Ben Moumen, H. Serghini Caid, M. Berrabah, E. Tahri. J. Mater. Environ. Sci. 8 (2017) 42644272.

[21]. A. Allalout, D. Krichène, K. Methenni, A. Taamalli, I. Oueslati, D. Daoud, M. Zarrouk. Sci. Hortic. 120 (2009) 77-83.

[22]. J. Hermoso, A. Ninot, A. Romero, J. Tous. Calif. Agr. 65 (2011) 34-40.

[23]. A. Koutsaftakis, F. Kotsifakis, E. Stefanoudaki. Olivae 81 (2000) 20-25.

[24]. D. Ollivier, J. Artaud, C. Pinatel, J.P. Durbec, M. Guérère. J. Agric. Food. Chem. 51 (2003) 5723-5731.

[25]. F. Mansouri, A.Ben Moumen, G. Richard, M.-L. Fauconnier, M. Sindic, H.S. Caid, A. Elamrani. OCL. 24 (2017) A501.

[26]. R. Aparicio, G. Luna. Eur. J. Lipid Sci. Technol. 104 (2002) 614-627. 